\title{
Interaction Studies between Newly Synthesized Photosensitive Polymer and Ionic Liquids
}

\author{
In Tae Kim, ${ }^{1}$ Gi-Chung Kwon, ${ }^{2}$ Eun Ha Choi, ${ }^{2}$ Seung-Hyun Lee, ${ }^{3}$ \\ Young Sun Kim, ${ }^{1}$ Jong Hyun Kim, ${ }^{1}$ Ju Hyon Cha, ${ }^{1}$ Sung Ho Kim, ${ }^{1}$ and Pankaj Attri ${ }^{2}$ \\ ${ }^{1}$ Department of Chemistry, Kwangwoon University, Seoul 139-701, Republic of Korea \\ ${ }^{2}$ Plasma BioScience Research Center, Department of Electrophysics, Kwangwoon University, Seoul 139-701, Republic of Korea \\ ${ }^{3}$ Graduate School of Information Contents, Kwangwoon University, Seoul 139-701, Republic of Korea \\ Correspondence should be addressed to In Tae Kim; itkim@kw.ac.kr and Pankaj Attri; chem.pankaj@gmail.com
}

Received 7 March 2015; Accepted 2 June 2015

Academic Editor: Beng T. Poh

Copyright (C) 2015 In Tae Kim et al. This is an open access article distributed under the Creative Commons Attribution License, which permits unrestricted use, distribution, and reproduction in any medium, provided the original work is properly cited.

\begin{abstract}
In this information age, different kinds of photosensitive materials have been used in the manufacture of information storage devices. But these photosensitive materials have the bane of low diffraction efficiency. In order to solve this problem, we have synthesized a novel photosensitive polymer from epoxy-based azopolymers (with three types of azochromophores). Furthermore, we have studied the interaction between this newly synthesized azopolymer and ionic liquids (ILs). For this purpose, we have used the ammonium and imidazolium families of ILs, such as diethylammonium dihydrogen phosphate (DEAP), tributylammonium methyl sulfate (TBMS), triethylammonium 4-aminotoluene-3-sulfonic acid (TASA), and 1-methylimidazolium chloride ([Mim]Cl). To investigate the molecular interaction between azopolymer and ILs, we have used the following spectroscopic methods of analysis: UV-visible spectroscopy, photoluminescence (PL) spectroscopy, Fourier transformed infrared spectroscopy (FT-IR), and confocal Raman spectroscopy. In this study, we have developed new photosensitive materials by combining polymer with ILs.
\end{abstract}

\section{Introduction}

In this study, we have described cost-effective methods used to store, generate, and transmit data speedily [1]. Although diverse technologies are being used for information storage, photosensitive materials are the most popular ones. The optical reflection of photosensitive materials can be modified by metallic and polymeric lasers [2,3]. Photopolymers and silver halide materials have high sensitivity and excellent resolution, so they are used as holographic recording materials [4]. However, in the past few years, azopolymers have attracted the attention of several researchers as they have applications in diverse fields [1-4]. An azopolymer film induces anisotropic effect when exposed to light. Therefore, this nonlinear polymer film is one of the most promising holographic recording materials. Azopolymers also have many other advantageous properties, such as photoinduced birefringence, photoinduced phase transition, photomechanical deformation of thin films, and surface relief-grating (SRG) formation [5-11]. These properties can be correlated with photoinduced anisotropic effects through which the transisomer (more stable) of azo group gets excited and undergoes a transition to the cis-form (less stable). The energy for the transition is provided by the following diverse phenomena: the dipolar interaction with the optically induced electric field gradient $[12,13]$, the photoisomerization of azobenzene chromophores that undergo a translational diffusion [14], the molecular alignment that brings about a mean-field force [15], and the photomechanical effect occurring in thin films [16]. The polymer with such properties has diverse applications in sensors, actuators, optical storage devices, and other data storage devices.

However, some azopolymers still cannot induce high quality effects through photoinduced anisotropy, which is essential for the practical use of optical storage devices [1719]. Cui and Zhao have reported that a stable photoinduced birefringence can be detected in an azopyridine liquid crystalline polymer [20]. He et al. have devised different 
excitation regimes of nonlinear absorption (NLA) in azocontaining ion liquid crystal polymer [21]. Li et al. [22] have explored the photoorientation properties of liquid crystalline azodendrimer using pulsed irradiation. Ionic liquids (ILs) are another class of liquid crystals that are currently used for producing photoinduced anisotropy. ILs are defined as classical molten salts having low melting point [2328]. In recent years, Pan et al. have reported how they developed reversibility and long-term optical storage capacity in azo-containing IL crystals [29]. Furthermore, Zhao et al. [30] have also reported that the film made from azocontaining, IL-crystalline polymer exhibited large nonlinear refraction and negligible nonlinear absorption. After perusing through these research studies involving azopolymer and azo-containing, IL-crystalline polymer, we studied the interaction between the newly synthesized, epoxybased azopolymer and ILs (ammonium and imidazolium families) using photoluminescence (PL) and UV-visible, confocal Raman, and FT-IR spectroscopies. In this study, we have used the ammonium and imidazolium families of ILs, such as diethylammonium dihydrogen phosphate (DEAP), tributylmethylammonium sulfate (TBMS), triethylammonium 4-aminotoluene-3-sulfonic acid (TASA), and 1methylimidazolium chloride ([Mim]Cl).

\section{Experimental Section}

2.1. Materials. For conducting this experimental study, we purchased the following chemicals $4,4^{\prime}$-cyclohexylidene bisphenol, aniline, 4-bromobenzenediazonium tetrafluoroborate, and 4-nitrobenzenediazonium tetrafluoroborate (Sigma Aldrich, Co.; St. Louis, MO, USA). Epichlorohydrin was purchased from Sejinic, Co., Korea. All the other materials, reagents, and solvents were commercially available products, which were used without carrying out any further purification procedures.

2.2. Characterization. ${ }^{1} \mathrm{H}$ and ${ }^{13} \mathrm{C}$ NMR spectra were recorded at 400 and $100 \mathrm{MHz}$, respectively (JEOL, Tokyo, Japan). Infrared (IR) spectra were recorded using an MB104 FT-IR (ABB Bomem, Inc., Zurich, Switzerland). Atomic force microscopy (AFM) images were obtained using an XE100 AFM (Park Systems, Suwon, Republic of Korea). The major products were isolated by performing flash column chromatography on silica gel (230-400 mesh ASTM; Merck \& Co., Inc.; White House Station, NJ, USA) using a mixed solvent of chloroform/acetone (v/v = 95/5) as the eluent. Gel permeation chromatograph (GPC) data was obtained using a Waters 1515 (Waters). Differential scanning calorimetry (DSC) curve was obtained using Jade DSC (PerkinElmer, Waltham, MA, USA). In this experiment, the samples were analyzed on a diode-pumped solid state (DPSS) laser (Genesis CX-Series SLM; Coherent Lasers, Santa Clara, CA, USA).

Figure 1 illustrates the synthesis of the polymer. The detailed experimental procedure of synthesis is described below.

\subsection{Synthesis of the Polymer}

2.3.1. Synthesis of Monomer. 4,4'-Cyclohexylidene bisphenol was dissolved in epichlorohydrin, and the solution was stirred at room temperature. Then, an aqueous solution of sodium hydroxide was added, and the resultant homogeneous mixture (solution) was stirred for $6 \mathrm{~h}$. This solution was evaporated to isolate epichlorohydrin, which was then dissolved in ethyl acetate. Finally, the solution was washed five times with deionized water. The combined organic extracts were dried over $\mathrm{MgSO}_{4}$ and evaporated to discard ethyl acetate and deionized water from the homogeneous mixture (solution). The residue was purified by column chromatography using silica gel as the absorbent and the mixed solvent of chloroform/acetone ( $\mathrm{v} / \mathrm{v}=95 / 5)$ as the eluent. With this chromatographic technique, we obtained about $48.9 \%$ of colorless viscous oil. The structure of this viscous oil was characterized by ${ }^{1} \mathrm{H}$ NMR, ${ }^{13} \mathrm{C}$ NMR, and FT-IR. The results of NMR spectroscopic analysis were as follows: ${ }^{1} \mathrm{H}$ NMR $\left(400 \mathrm{MHz}, \mathrm{CDCl}_{3}\right) \delta 7.14(\mathrm{~d}, 4 \mathrm{H}), 6.80(\mathrm{~d}, 4 \mathrm{H}), 4.15(\mathrm{~d}, 1 \mathrm{H})$, $4.12(\mathrm{~d}, 1 \mathrm{H}), 3.91(\mathrm{q}, 2 \mathrm{H}), 3.29(\mathrm{~m}, 2 \mathrm{H}), 2.84(\mathrm{t}, 2 \mathrm{H}), 2.71(\mathrm{q}$, $2 \mathrm{H}), 2.20(\mathrm{~s}, 4 \mathrm{H}), 1.53(\mathrm{~s}, 6 \mathrm{H}) ;{ }^{13} \mathrm{C}$ NMR $\left(100 \mathrm{MHz}, \mathrm{CDCl}_{3}\right)$ $\delta 156.09,141.34,127.77,114.07,77.19,68.36,49.66,44.13,37.15$, 26.08, 22.66; IR (KBr) 3053, 3001, 2933, 2856, 1606, 1579, 1508, $1454,1348,1243,1184,1035,912,823 \mathrm{~cm}^{-1}$.

2.3.2. Synthesis of Precursor Polymer. Equimolar quantities of synthesized monomer and aniline were homogeneously mixed at room temperature, and then this mixture was gradually heated at $110^{\circ} \mathrm{C}$. Thereafter, this homogeneous mixture was stirred at $110^{\circ} \mathrm{C}$ for $48 \mathrm{~h}$. The product was washed several times with pure methanol to remove the moiety of low molecular weight. The polymer was then collected and dried under vacuum at $50^{\circ} \mathrm{C}$ for $12 \mathrm{~h}$. Using differential scanning calorimetry (DSC), we found that $T_{g}$ of polymer was $90.28^{\circ} \mathrm{C}$. The number average molecular weight and weight average molecular weight of the polymer were estimated to be 6,720 and 10,670, respectively. With the help of gel permeation chromatography (GPC), we found that the polydispersity index of the polymer was 1.58 . The results of NMR spectroscopic analysis were as follows: ${ }^{1} \mathrm{H}$ NMR $\left(400 \mathrm{MHz}, \mathrm{DMSO}-\mathrm{d}_{6}\right) \delta 7.12(\mathrm{~d}, 2 \mathrm{H}), 7.03(\mathrm{~d}, 2 \mathrm{H}), 6.80(\mathrm{~d}$, $2 \mathrm{H}), 6.70(\mathrm{~d}, 2 \mathrm{H}), 6.53(\mathrm{~m}, 1 \mathrm{H}), 5.33(\mathrm{~s}, 1 \mathrm{H}), 5.13(\mathrm{~s}, 1 \mathrm{H}), 4.04$ (m, 2H), 3.85 (s, 4H), 3.43-3.68 (broad, 4H), $2.14(\mathrm{~s}, 4 \mathrm{H}), 1.41$ $(\mathrm{s}, 6 \mathrm{H}) ;{ }^{13} \mathrm{C}$ NMR $\left(100 \mathrm{MHz}, \mathrm{CDCl}_{3}\right) \delta 156.18,148.12,148.02$, $140.51,129.18,128.92,127.99,127.59,114.16,112.32,112.06,111.66$, $70.03,66.35,55.02,54.75,48.56,44.61,44.22,36.58,36.31$, 22.48; IR (KBr) broad 3328, 3064, 3035, 2933, 2858, 1598, 1509, $1465,1363,1247,1184,1108,1037,908,823,732,692 \mathrm{~cm}^{-1}$.

2.3.3. Synthesis of Azopolymer-A. Aniline was dissolved in a homogeneous mixture of tetrahydrofuran, glacial acetic acid, sulfuric acid, and deionized water. Thereafter, an aqueous solution of sodium nitrite was added dropwise to this homogeneous mixture (solution) at $5^{\circ} \mathrm{C}$. Then, this homogeneous mixture solution was stirred at $5^{\circ} \mathrm{C}$ for 10 minutes. We prepared a diazonium salt of sulfanilic acid solution. Subsequently, this synthesized precursor of polymer 
<smiles>Oc1ccc(C2(c3ccc(O)cc3)CCCCC2)cc1</smiles><smiles>Cc1ccccc1N(C)CC(O)COc1ccc(C2(c3ccc(OCC(O)CN(C)c4ccccc4)cc3)CCCCC2)cc1</smiles><smiles>[R]c1ccc([N+]#N)cc1</smiles><smiles>[R]c1ccc(N=Nc2ccc(N(CC(C)C)CC(O)COc3ccc(C4(c5ccc(OCC(C)O)cc5)CCCCC4)cc3)cc2)cc1</smiles>

Polymer R

Polymer A $\mathrm{H}$

Polymer B Br

Polymer C $\mathrm{NO}_{2}$

FIGURE 1: Schematic view of the synthesis of azopolymers.

was dissolved in $60 \mathrm{~mL}$ of tetrahydrofuran, and this mixture was stirred at $0^{\circ} \mathrm{C}$. Furthermore, the diazonium salt solution was added dropwise to the mixture of precursor polymer and stirred vigorously at $0^{\circ} \mathrm{C}$ for $18 \mathrm{~h}$. The resultant mixture was evaporated to eliminate tetrahydrofuran. The product was washed with pure diethyl ether and deionized water several times. Then, we dried this product under vacuum at $70^{\circ} \mathrm{C}$ for at least $24 \mathrm{~h}$. Using DSC, we found that the $T_{g}$ of the polymer was $86.77^{\circ} \mathrm{C}$. The number average molecular weight and weight average molecular weight of the polymer were estimated to be 5,860 and 8,300, respectively. With the help of GPC, we found that the polydispersity index of this polymer was 1.37. The results of NMR spectroscopic analysis were as follows: ${ }^{1} \mathrm{H}$ NMR (400 MHz, DMSO-d 6 ) $\delta 7.71(\mathrm{~d}, 2 \mathrm{H}), 7.44$ $(\mathrm{d}, 2 \mathrm{H}), 7.12(\mathrm{~d}, 4 \mathrm{H}), 7.07$ (d, 2H), $6.83(\mathrm{~d}, 4 \mathrm{H}), 6.69(\mathrm{~d}, 2 \mathrm{H})$, $5.76(\mathrm{~s}, 1 \mathrm{H}), 5.33(\mathrm{~s}, 1 \mathrm{H}), 4.06(\mathrm{~m}, 2 \mathrm{H}), 3.87$ (s, 4H), 3.13-3.68 (broad, $4 \mathrm{H}), 2.13(\mathrm{~s}, 4 \mathrm{H}), 1.42(\mathrm{~s}, 6 \mathrm{H}) ;{ }^{13} \mathrm{C} \mathrm{NMR}(100 \mathrm{MHz}$, $\left.\mathrm{CDCl}_{3}\right) \delta 156.22,148.85,147.66,141.11,140.55,129.89,129.22$, $128.67,127.64,115.39,115.01,114.68,114.20,112.55,111.70,111.12$, $79.29,70.07,66.39,54.79,53.56,44.25,36.35,30.82,25.95$,
22.52; IR (KBr) broad 3361, 3060, 3037, 2937, 2862, 1600, 1503, $1460,1361,1243,1182,1114,1060,908,823,748,694 \mathrm{~cm}^{-1}$.

2.3.4. Synthesis of Azopolymer-B. We dissolved 4-bromobenzenediazonium tetrafluoroborate in a solution of tetrahydrofuran and deionized water. Then, we prepared a diazonium salt solution. Thereafter, the synthesized precursor of polymer was dissolved in $60 \mathrm{~mL}$ of tetrahydrofuran and stirred at $0^{\circ} \mathrm{C}$. The diazonium salt solution was added dropwise to a solution of precursor polymer, and then it was stirred continuously at $0^{\circ} \mathrm{C}$ for $18 \mathrm{~h}$. The resultant mixture was evaporated to eliminate tetrahydrofuran. The product was washed with pure diethyl ether and deionized water several times. Finally, the product was dried under vacuum at $70^{\circ} \mathrm{C}$ for at least $24 \mathrm{~h}$. The results of spectroscopic analysis were as follows: ${ }^{1} \mathrm{H}$ NMR $\left(400 \mathrm{MHz}, \mathrm{DMSO}-\mathrm{d}_{6}\right) \delta 7.68(\mathrm{~d}, 2 \mathrm{H}), 7.66(\mathrm{~d}, 2 \mathrm{H}), 7.36(\mathrm{~d}$, $2 \mathrm{H}), 7.11(\mathrm{~d}, 4 \mathrm{H}), 6.80(\mathrm{~d}, 2 \mathrm{H}), 6.68(\mathrm{~d}, 4 \mathrm{H}), 5.39(\mathrm{~s}, 1 \mathrm{H}), 5.28$ (s, 1H), 4.08 (m, 2H), 3.77-3.88 (broad, 6H), $3.54(\mathrm{~m}, 2 \mathrm{H}), 2.14$ (s, 4H), 1.38 (s, 6H); IR (KBr) broad 3362, 3063, 3034, 2935, 
$2861,1601,1502,1461,1363,1242,1181,1117,1061,907,824,748$, $695 \mathrm{~cm}^{-1}$.

2.3.5. Synthesis of Azopolymer-C. We dissolved 4-nitrobenzenediazonium tetrafluoroborate in a solution of tetrahydrofuran and deionized water. Thus, we prepared a diazonium salt solution. Subsequently, the synthesized precursor of polymer was dissolved in $60 \mathrm{~mL}$ of tetrahydrofuran, and the resultant mixture was stirred at $0^{\circ} \mathrm{C}$. Then, the diazonium salt solution was added dropwise to the mixture of precursor polymer. The resultant suspension was stirred at $0^{\circ} \mathrm{C}$ for $18 \mathrm{~h}$. The resultant mixture was evaporated to eliminate tetrahydrofuran. The product was washed with pure diethyl ether and deionized water several times. Finally, we dried this product under vacuum at $70^{\circ} \mathrm{C}$ for at least $24 \mathrm{~h}$. The results of NMR spectroscopic analysis were as follows: ${ }^{1} \mathrm{H}$ NMR $\left(400 \mathrm{MHz}, \mathrm{DMSO}-\mathrm{d}_{6}\right) \delta 8.31(\mathrm{~d}, 2 \mathrm{H}), 7.87(\mathrm{~d}, 2 \mathrm{H}), 7.75(\mathrm{~d}, 2 \mathrm{H})$, $7.11(\mathrm{~d}, 4 \mathrm{H}), 6.89(\mathrm{~d}, 2 \mathrm{H}), 6.80(\mathrm{~d}, 4 \mathrm{H}), 5.42(\mathrm{~s}, 1 \mathrm{H}), 5.30(\mathrm{~s}$, $1 \mathrm{H}), 4.08(\mathrm{~m}, 2 \mathrm{H}), 3.78-3.89$ (broad, $6 \mathrm{H}), 3.56(\mathrm{~m}, 2 \mathrm{H}), 2.13$ (s, 4H), 1.38 (s, 6H); IR (KBr) broad 3355, 3051, 3035, 2931, 2861, 1600, 1511, 1460, 1367, 1247, 1187, 1111, 1044, 901, 827, 743, $692 \mathrm{~cm}^{-1}$.

2.4. Synthesis of ILs. In our previous study, we have described the synthesis of tributylammonium methyl sulfate $\left[\mathrm{N}_{1444}\right]\left[\mathrm{MeSO}_{4}\right]$ and diethylammonium dihydrogen phosphate (DEAP) $[24,27,28]$.

2.4.1. Synthesis of Triethylammonium 4-Aminotoluene-3sulfonic Acid (TASA). The synthesis of ionic liquids was carried out in a $250 \mathrm{~mL}$ round-bottomed flask, which was immersed in a water-bath and fitted with a reflux condenser. 4-Aminotoluene-3-sulfonic acid ( $1 \mathrm{~mol}$ ) was added dropwise to triethylamine $(1 \mathrm{~mol})$ at $70^{\circ} \mathrm{C}$ for $1 \mathrm{~h}$. Then, this reaction mixture was heated at $80^{\circ} \mathrm{C}$ and continuously stirred for $2 \mathrm{~h}$. Thus, we ensured that the synthesis reaction proceeded to completion. Thereafter, this reaction mixture was dried at $80^{\circ} \mathrm{C}$ till the weight of the residue became constant. The sample was analyzed by Karl Fisher titration, which detected very low levels of water (below $70 \mathrm{ppm}$ ). The total yield of TASA was $91 \%$ with this method. The results of NMR spectroscopic analysis were as follows: ${ }^{1} \mathrm{H}$ NMR $\left(\mathrm{CDCl}_{3}\right): \delta$ (ppm) $1.13(\mathrm{~s}, 9 \mathrm{H}), 2.22(\mathrm{~s}, 3 \mathrm{H}), 3.10(\mathrm{~s}, 6 \mathrm{H}), 5.14(\mathrm{~s}, 2 \mathrm{H}), 6.60$ (s, 1H), $6.91(\mathrm{~s}, 1 \mathrm{H}), 7.57(\mathrm{~s}, 1 \mathrm{H}), 10.39(\mathrm{~s}, 1 \mathrm{H})$.

2.5. Preparation of Polymer Film. The concentration of azopolymer-C was typically $12 \mathrm{wt} \%$ in a homogeneous solution of anhydrous tetrahydrofuran. This solution was filtered through $0.45 \mu \mathrm{m}$ membranes and bar-coated onto normal glass slides. The average thickness of this film was $10 \mu \mathrm{m}$. Before being used, these coated films were dried at $100^{\circ} \mathrm{C}$ in an oven for $24 \mathrm{~h}$.

\section{Results and Discussion}

3.1. Synthesis and UV-Vis Studies of the Azopolymers. In this work, we have synthesized three novel azopolymers that can

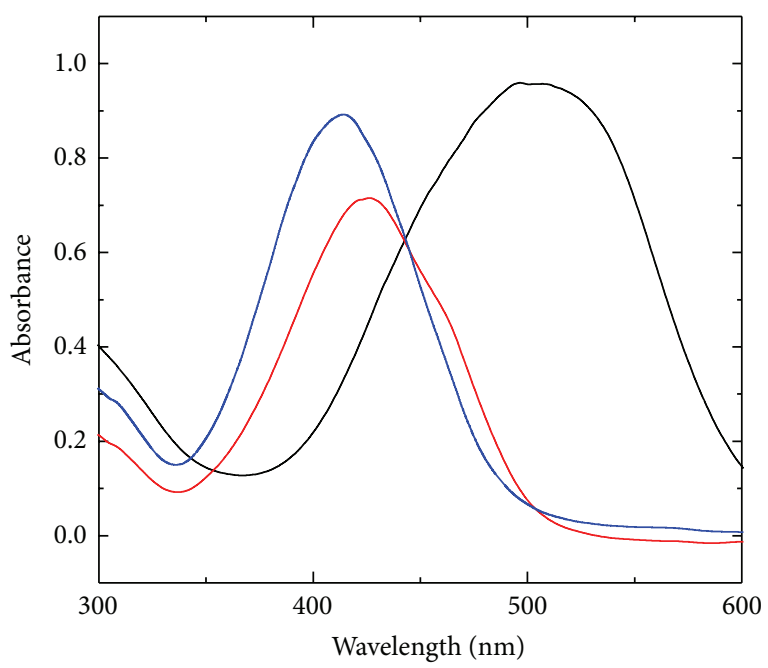

FIGURE 2: UV-visible absorption spectra of azopolymer-A (blue color), azopolymer-B (red color), and azopolymer-C (black color) in THF solution.

be used as holographic recording materials. Three different types of azochromophores (azopolymer-A/azopolymer$\mathrm{B}$ /azopolymer-C) were developed from the precursor polymer using azo coupling reaction (see Figure 1). Using the functionality of a polymer, we incorporated different types of azochromophores into the precursor polymer [31,32]. The polymers exhibited $T_{g}$ value at around $80-90^{\circ} \mathrm{C}$. While carrying out polymerization of precursor polymers, we maintained a temperature of $110^{\circ} \mathrm{C}$ to eliminate side reactions, such as cross-linking polymerization. Had the temperature risen above $110^{\circ} \mathrm{C}$, cross-linking polymerization would have occurred, and the solubility of azopolymers in common organic solvents would have been very low. Therefore, the synthesized azopolymers were not long chain polymers. Instead, they were short chain polymers, having a molecular weight of around 10,000. The degree of functionalization in the three series of azopolymers was determined by ${ }^{1} \mathrm{H}$ NMR analysis. In this analysis, we found that the peak at the $p$-position of precursor polymers disappeared, while peaks ascribed to the new benzene ring appeared.

For understanding the efficiency of these polymers (azopolymer-A/azopolymer-B/azopolymer-C), we used UVvisible spectroscopy. Figure 2 displays the $\lambda_{\max }$ values for the azopolymer in THF solution. The $\lambda_{\max }$ value of the $\pi-\pi^{*}$ absorption band is shifted to a longer wavelength in the visible region, thereby indicating the presence of donor-acceptor type azochromophores. The $\lambda_{\max }$ values for azopolymer$A$, azopolymer-B, and azopolymer-C were $414 \mathrm{~nm}, 426 \mathrm{~nm}$, and $502 \mathrm{~nm}$, respectively. This indicates that $\lambda_{\max }$ values get strongly influenced by the p-position of azobenzene units, which act as electron acceptors. Hence, we decided to use azopolymer-C, which exhibited a maximum wavelength shift with ILs. To investigate the molecular interaction between ILs and azopolymers, we used PL, UV-visible, and Raman spectroscopies. 


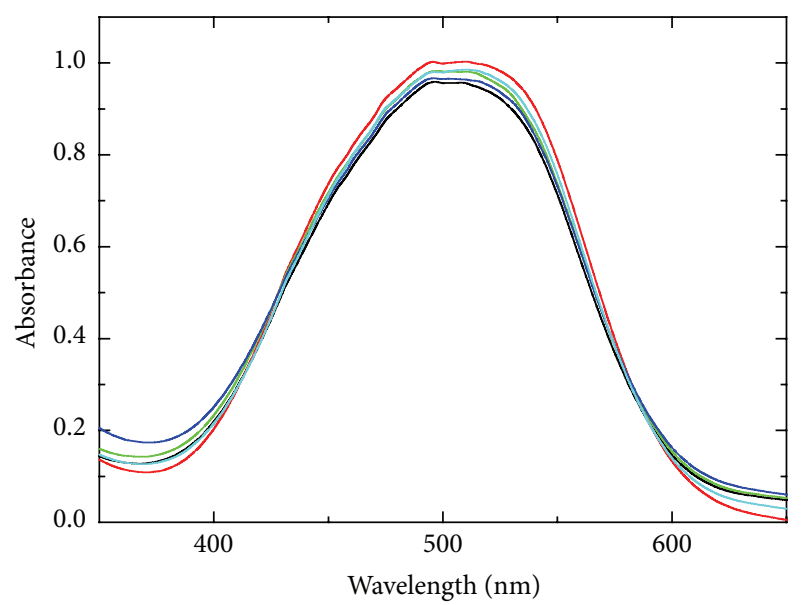

(a)

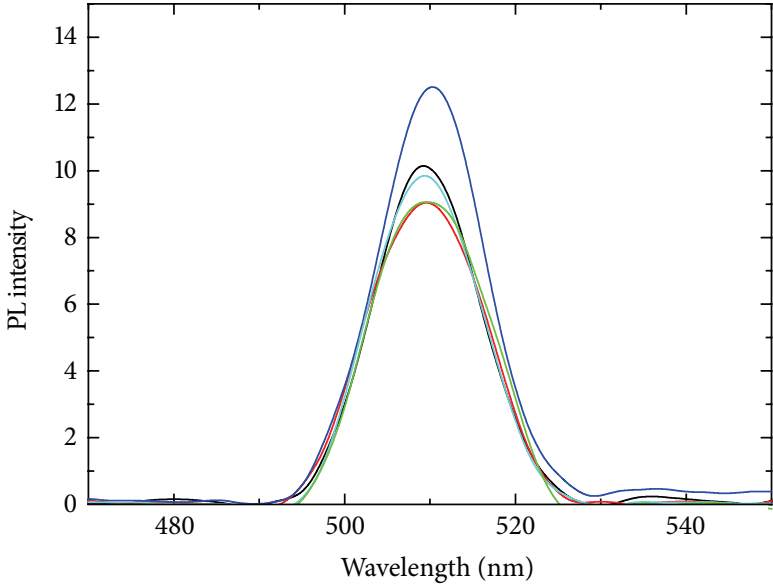

(b)

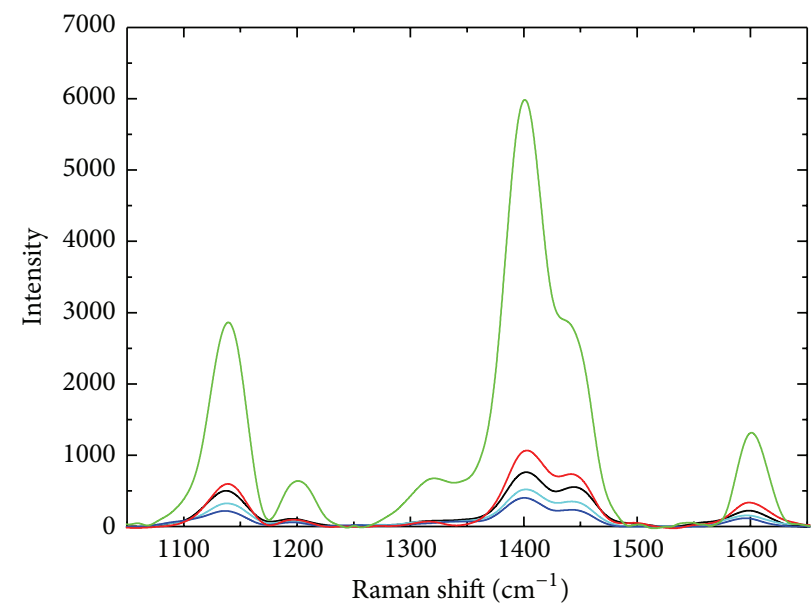

(c)

Figure 3: (a) UV-visible absorption spectra, (b) photoluminescence (PL) spectra, and (c) confocal Raman spectra of azopolymer-C (black), azopolymer-C + DEAP (red), azopolymer-C + TBMA (green), azopolymer-C + TASA (blue), and azopolymer-C + $[\mathrm{Mim}] \mathrm{Cl}(\mathrm{cyan})$.

3.2. Molecular Interaction Study of Azopolymer with ILs Using $P L, U V$-Visible, and Confocal Raman Spectroscopies. The miscibility factor is governed by the molecular interaction between azopolymer-C and ILs. With the help of UV-visible spectroscopy, we found that there was a significant molecular interaction between the synthesized azopolymer-C and ILs. As shown in Figure 3(a), compared to only polymer, there is a slight red shift in case of all ILs interacting with the polymer. The azopolymer depicted a maximum absorbance at $502 \mathrm{~nm}$, while azopolymer-C + DEAP exhibited maximum absorbance at $518 \mathrm{~nm}$. Compared with the azopolymer, the intensity of absorption was much higher for azopolymer- $\mathrm{C}+$ DEAP. Moreover, azopolymer-C + TASA showed maximum absorbance at $511 \mathrm{~nm}$, but there was no increase in the intensity of absorbed light. Instead, the [Mim] Cl (protic imidazolium IL) + polymer exhibited red shift with a maximum absorbance at $513 \mathrm{~nm}$; this solution mixture also showed a slight increase in the intensity of absorbed light. The red shift and slight increase in intensity of absorption by $[\mathrm{Mim}] \mathrm{Cl}+$ azopolymer suggest that $[\mathrm{Mim}] \mathrm{Cl}$ interacts with azopolymer.
A red shift with maximum absorbance at $513 \mathrm{~nm}$ is due to the interaction of aprotic ammonium IL TBMA, with the polymer.

In order to have in-depth knowledge of optical properties of polymer and polymer + ILs, we conducted PL spectroscopy. The results of this analysis are displayed in Figure 3(b). The PL for the polymer was observed approximately at $509 \mathrm{~nm}$. On the other hand, azopolymer-C + DEAP showed maximum PL at approximately $510 \mathrm{~nm}$ with quenching intensity. This indicates that DEAP undergoes a slight change in its PL properties after chemically interacting with azopolymer-C. Furthermore, ammonium IL TBMA interacts with azopolymer-C, showing a decrease in its intensity of absorption and red shift as compared to the polymer (alone). But, in this case, there is no shift when compared with azopolymer-C + DEAP. Moreover, the ammonium IL TASA combination with azopolymer- $\mathrm{C}$ exhibited a red shift and an increase in intensity. But there was no significant shift in wavelength and intensity for the imidazolium based IL [Mim] Cl when compared with the polymer alone. To further 
TABLE 1: FT-IR spectroscopy analysis of the azopolymer-C and azopolymer-C + ILs.

\begin{tabular}{|c|c|c|c|c|c|}
\hline & Azopolymer-C & $\begin{array}{l}\text { Azopolymer-C } \\
\text { + DEAP }\end{array}$ & $\begin{array}{c}\text { Azopolymer-C } \\
+[\mathrm{Mim}] \mathrm{Cl}\end{array}$ & $\begin{array}{c}\text { Azopolymer-C } \\
+ \text { TBMS }\end{array}$ & $\begin{array}{c}\text { Azopolymer-C } \\
\text { + TASA }\end{array}$ \\
\hline $\mathrm{O}-\mathrm{H}$ & $\begin{array}{c}3500-3150 \\
\text { (broad) }\end{array}$ & 3500 & $\begin{array}{c}3650-3200 \\
\text { (broad) }\end{array}$ & $\begin{array}{c}3600-3150 \\
\text { (broad) }\end{array}$ & 3500 \\
\hline $\mathrm{C}=\mathrm{C}-\mathrm{H}$ & 3037 & 3036 & 3137 & 3137 & 3029 \\
\hline $\mathrm{C}-\mathrm{H}$ & 2931,2856 & 2975,2905 & 2956,2860 & 2968,2873 & 2989,2927 \\
\hline $\mathrm{C}=\mathrm{C}$ (aromatic) & 1598,1454 & 1600,1460 & 1583,1450 & 1600,1469 & 1600,1454 \\
\hline$-\mathrm{NO}_{2}$ (symmetric) & 1336 & 1336 & 1330 & 1334 & 1336 \\
\hline$-\mathrm{NO}_{2}$ (asymmetric) & 1508 & 1512 & 1512 & 1512 & 1506 \\
\hline $\mathrm{C}-\mathrm{N}$ (phenyl) & 1313 & 1313 & 1311 & 1310 & 1307 \\
\hline C-N (alkyl) & 1135 & 1134 & 1135 & 1135 & 1141 \\
\hline $\mathrm{C}-\mathrm{O}$ (phenyl) & 1242,1039 & 1242,1045 & 1247,1010 & 1255,1016 & 1232,1012 \\
\hline $\mathrm{C}-\mathrm{O}$ (alkyl) & 1101 & 1103 & 1087 & 1103 & 1107 \\
\hline Aromatic para substituent & 823 & 821 & 825 & 823 & 829 \\
\hline
\end{tabular}

elucidate the interaction between polymer and ILs, we used confocal Raman spectroscopy.

Confocal Raman microscopy is a more sophisticated technique; it estimates the vibrational energy of target solutes and eliminates the need of invasive monitoring aids [3335]. However, owing to the penetration of the polymeric membrane, the Raman signal was strongly diminished and the excited laser's signal was also strongly attenuated. Thus, the highly selective and sensitive laser can be directed inside azopolymer- $\mathrm{C}$ without causing any damage. As seen in Figure 3(c), significant peaks appear at 1136, 1202, 1402, and $1599 \mathrm{~cm}^{-1}$, corresponding to $\mathrm{C}-\mathrm{OH}, \mathrm{C}-\mathrm{O}-\mathrm{C}, \delta\left(\mathrm{CH}_{2}\right)$, $\delta\left(\mathrm{CH}_{3}\right)$ asymmetric, and $v\left(\mathrm{C}-\mathrm{NO}_{2}\right)$ groups, respectively, in the polymer. On other hand, the polymer + ILs showed a slight red shift, confirming the interaction between the polymer and ILs. In the case of protic ammonium DEAP IL + polymer, the Raman peaks were observed at 1141, 1202, 1403, and $1602 \mathrm{~cm}^{-1}$. These peaks also exhibited higher intensity when compared to the polymer alone. In case of TASA + polymer, Raman peaks were observed at 1142, 1202, 1403, and $1452 \mathrm{~cm}^{-1}$ with quenching intensity. These shifts clearly indicate that both protic ammonium ILs have interactions with azopolymer-C. Furthermore, wavelength shifts were also observed between protic imidazolium [Mim]Cl IL and polymer at $1141,1201,1402$, and $1598 \mathrm{~cm}^{-1}$. In case of aprotic ammonium IL TBMA + polymer, high intensity peaks were observed at 1139, 1201, 1401, and $1601 \mathrm{~cm}^{-1}$.

3.3. The Study of Molecular Interaction between Polymer and ILs Using FT-IR Spectroscopy. To understand the interaction between azopolymer-C and ILs, FT-IR spectroscopy study seemed to be useful tools. Figures S1S4 (FT-IR data of polymer and polymer-ILs mixture can be seen in Supplementary Material available online at http://dx.doi.org/10.1155/2015/461974) and Table 1 display the FT-IR spectra of azopolymer-C in the absence and presence of various ILs, respectively. Some shifts in the wavelength of azopolymer- $\mathrm{C}$ were observed after its interaction with ILs.
The band assignment is as follows: the absorption bands of $\mathrm{O}-$ $\mathrm{H}, \mathrm{C}=\mathrm{C}-\mathrm{H}, \mathrm{C}-\mathrm{H}, \mathrm{C}=\mathrm{C}$ (aromatic), $\mathrm{NO}_{2}$ (symmetric), $\mathrm{NO}_{2}$ (asymmetric), C-N (phenyl), C-N (alkyl), C-O (phenyl), C-O (alkyl), and aromatic p-substituent are at 3500-3150 (broad), 3037, (2931, 2856), (1598, 1454), 1336, 1508, 1313, 1135, $(1242,1039), 1101$, and $823 \mathrm{~cm}^{-1}$, respectively (Figure S1a). After the interaction of protic ammonium IL DEAP with the polymer, the absorption bands shifted to longer wavelength. For example, $\mathrm{C}-\mathrm{H}$ peak appeared at $2975,2905 \mathrm{~cm}^{-1}$, while $\mathrm{C}=\mathrm{C}$ (aromatic) peak appeared at $1600,1460 \mathrm{~cm}^{-1}$. The $\mathrm{NO}_{2}$ (asymmetric) peak occurred at $1512 \mathrm{~cm}^{-1}$, while C$\mathrm{O}$ (phenyl) peaks appeared at $1242,1045 \mathrm{~cm}^{-1}$. The $\mathrm{C}-\mathrm{O}$ (alkyl) appeared at $1103 \mathrm{~cm}^{-1}$ (Figure S1b). However, the remaining peaks did not change their intensity and position even after interaction with DEAP. Similarly, for other protic ammonium IL TASA, some peaks shifted to longer wavelength: the $\mathrm{C}-\mathrm{H}$ peak appeared at $2989,2927 \mathrm{~cm}^{-1}$, while the $\mathrm{C}=\mathrm{C}$ (aromatic) peak appeared at $1600,1454 \mathrm{~cm}^{-1}$. Furthermore, C-N (alkyl) was detected at $1141 \mathrm{~cm}^{-1}$, while $\mathrm{C}-\mathrm{O}$ (alkyl) was conspicuous at $1107 \mathrm{~cm}^{-1}$ (Figure S2). As seen in Table 1, some peaks shifted to lower wavelength but most peaks retained the same positions. Moreover, some peaks of protic imidazolium IL [ $\mathrm{Mim}] \mathrm{Cl}$ also shifted to longer wavelength: $\mathrm{C}=\mathrm{C}-\mathrm{H}$ peak appeared at $3137 \mathrm{~cm}^{-1}$, while $\mathrm{C}-\mathrm{H}$ peaks appeared at $2956,2860 \mathrm{~cm}^{-1}$. The $\mathrm{NO}_{2}$ (asymmetric) peak appeared at $1512 \mathrm{~cm}^{-1}$, while the peak at $825 \mathrm{~cm}^{-1}$ was ascribed to aromatic p-substituent. As seen in Figure S3, the remaining peaks either shifted to a lower wavelength or remained at the same position. In the aprotic ammonium IL TBMA + polymer, there were peaks that shifted to longer wavelength: the $\mathrm{C}-\mathrm{H}$ peak appeared at $2968,2873 \mathrm{~cm}^{-1}$, while $\mathrm{C}=\mathrm{C}$ (aromatic) peak appeared at $1600,1469 \mathrm{~cm}^{-1}$. As shown in Figure S4, the peak at $1512 \mathrm{~cm}^{-1}$ was attributed to $\mathrm{NO}_{2}$ (asymmetric vibration).

Among the three synthesized azopolymers, azopolymer$\mathrm{C}$ exhibited the longest wavelength shift in UV-visible spectroscopic analysis, which was attributed to the conjugative and inductive effects of both ground state $(\pi)$ and excited 
state $\left(\pi^{*}\right)$ electrons. The results of UV-visible spectroscopy revealed that both protic and aprotic ILs interacted extensively with the polymeric surface. However, the high intensity peaks of protic ammonium ILs appeared at longer wavelength after interacting with the polymer. Moreover, UVvisible spectroscopy showed that both protic ammonium ILs (DEAP and TASA) interacted with azopolymer-C to different extents. Similarly, the PL spectroscopy results revealed that, compared with imidazolium IL, the change in PL properties was significant in ammonium ILs. On the other hand, peak shifts in the Raman spectra reveal that both protic and aprotic ILs of ammonium and imidazolium families strongly interact with azopolymer- $\mathrm{C}$ and modify polymeric properties. The FT-IR results also support the Raman data, indicating that there is an interaction between all ILs and azopolymer$\mathrm{C}$ due to which the absorption peaks shift to longer or shorter wavelengths. In various spectroscopic studies, the shift in the wavelengths of peaks has been attributed to the various kinds of interaction between the azopolymer and ILs, such as hydrogen bonding, Van der Waal's interaction, and Coulombic interaction. Hence, azopolymer + IL can be used as a holographic material for capturing images. This study provides new outlook to the combined use of azopolymer + IL in various holographic devices.

\section{Conclusion}

In this extensive experimental study, we successfully synthesized three new photosensitive materials. Among them, azopolymer-C has the maximum $\pi-\pi^{*}$ emission. Furthermore, to explore the interactions between polymer and ILs, we used the following analytical techniques: UV-visible, FTIR, and confocal Raman spectroscopies. Then, we inferred that, compared to protic imidazolium ILs, protic and aprotic ammonium ILs had a greater tendency to form hydrogen bonds. To the best of our knowledge, the azopolymer and IL mixture has not been analyzed for this first time in this study. Hence, the results of this novel study seem to be beneficial in the field of polymer chemistry and holographic research.

\section{Conflict of Interests}

The authors declare that they do not have any conflict of interests.

\section{Acknowledgments}

The authors gratefully acknowledge the grants received from the National Research Foundation of Korea (NRF), which is an organization funded by the government of Korea (MSIP) (NRF-2010-0027963). This work was supported by the Department of New \& Renewable Energy, Korea Institute of Energy Technology Evaluation and Planning (KETEP). The authors also received a financial grant from the Korean government's Ministry of Knowledge Economy (no. 96002011003). The financial grant was awarded under the project "Full Color 360 Degree 3D Holographic Video Making Technology." Furthermore, the authors are also thankful to the Ministry of Culture, Sports, and Tourism (MCST) and Korea Creative Contents Agency (KOCCA), which oversees the Culture, Technology, Research and Development Program 2012 at Kwangwoon University. This research was conducted in 2015 during the sabbatical research year of Kwangwoon University.

\section{References}

[1] S. Xie, A. Natansohn, and P. Rochon, "Recent developments in aromatic azo polymers research," Chemistry of Materials, vol. 5, no. 4, pp. 403-411, 1993.

[2] J. A. Delaire and K. Nakatani, "Linear and nonlinear optical properties of photochromic molecules and materials," Chemical Reviews, vol. 100, no. 5, pp. 1817-1845, 2000.

[3] A. Natansohn and P. Rochon, "Photoinduced motions in azocontaining polymers," Chemical Reviews, vol. 102, no. 11, pp. 4139-4175, 2002.

[4] T. Ikeda, J.-I. Mamiya, and Y. Yu, "Photomechanics of liquidcrystalline elastomers and other polymers," Angewandte Chemie-International Edition, vol. 46, no. 4, pp. 506-528, 2007.

[5] T. Ikeda, S. Horiuchi, D. B. Karanjit, S. Kurihara, and S. Tazuke, "Photochemically induced isothermal phase transition in polymer liquid crystals with mesogenic phenyl benzoate side chains. 2. Photochemically induced isothermal phase transition behaviors," Macromolecules, vol. 23, no. 1, pp. 42-48, 1990.

[6] T. Todorov, L. Nikolova, and N. Tomova, "Polarization holography 1: a new high-efficiency organic material with reversible photoinduced birefringence," Applied Optics, vol. 23, no. 23, pp. 4309-4312, 1984.

[7] P. Rochon, E. Batalla, and A. Natansohn, "Optically induced surface gratings on azoaromatic polymer films," Applied Physics Letters, vol. 66, pp. 136-138, 1995.

[8] D. Y. Kim, S. K. Tripathy, L. Li, and J. Kumar, "Laser-induced holographic surface relief gratings on nonlinear optical polymer films," Applied Physics Letters, vol. 66, no. 10, pp. 1166-1168, 1995.

[9] M.-H. Li, P. Keller, B. Li, X. Wang, and M. Brunet, "Light-driven side-on nematic elastomer actuators," Advanced Materials, vol. 15, no. 7-8, pp. 569-572, 2003.

[10] Y. L. Yu, M. Nakano, and T. Ikeda, "Photomechanics: directed bending of a polymer film by light," Nature, vol. 425, no. 6954, p. 145, 2003.

[11] M. Camacho-Lopez, H. Finkelmann, P. Palffy-Muhoray, and M. Shelley, "Fast liquid-crystal elastomer swims into the dark," Nature Materials, vol. 3, no. 5, pp. 307-310, 2004.

[12] J. Kumar, L. Li, X. L. Jiang, D.-Y. Kim, T. S. Lee, and S. Tripathy, "Gradient force: the mechanism for surface relief grating formation in azobenzene functionalized polymers," Applied Physics Letters, vol. 72, no. 17, pp. 2096-2098, 1998.

[13] S. P. Bian, J. M. Williams, D. Y. Kim et al., "Photoinduced surface deformations on azobenzene polymer films," Journal of Applied Physics, vol. 86, no. 8, pp. 4498-4508, 1999.

[14] P. Lefin, C. Fiorini, and J.-M. Nunzi, "Anisotropy of the photoinduced translation diffusion of azobenzene dyes in polymer matrices," Pure and Applied Optics, vol. 7, no. 1, pp. 71-82, 1998.

[15] T. G. Pedersen, P. M. Johansen, N. C. R. Holme, P. S. Ramanujam, and S. Hvilsted, "Mean-field theory of photoinduced formation of surface reliefs in side-chain azobenzene polymers," Physical Review Letters, vol. 80, no. 1, pp. 89-92, 1998. 
[16] O. M. Tanchak and C. J. Barrett, "Light-induced reversible volume changes in thin films of azo polymers: the photomechanical effect," Macromolecules, vol. 38, no. 25, pp. 1056610570, 2005.

[17] D. H. Han, X. Tong, Y. Zhao, and T. Galstian, "Cyclic azobenzene-containing side-chain liquid crystalline polymers: synthesis and topological effect on mesophase transition, order, and photoinduced birefringence," Macromolecules, vol. 43, no. 8, pp. 3664-3671, 2010.

[18] Y. Zakrevskyy, J. Stumpe, B. Smarsly, and C. F. J. Faul, "Photoinduction of optical anisotropy in an azobenzene-containing ionic self-assembly liquid-crystalline material," Physical Review E, vol. 75, no. 3, Article ID 031703, 2007.

[19] S. F. Xiao, X. M. Lu, Q. H. Lu, and B. Su, "Photosensitive liquidcrystalline supramolecules self-assembled from ionic liquid crystal and polyelectrolyte for laser-induced optical anisotropy," Macromolecules, vol. 41, no. 11, pp. 3884-3892, 2008.

[20] L. Cui and Y. Zhao, "Azopyridine side chain polymers: an efficient way to prepare photoactive liquid crystalline materials through self-assembly," Chemistry of Materials, vol. 16, no. 11, pp. 2076-2082, 2004.

[21] T. C. He, C. S. Wang, J. W. Zhang, X. Q. Zhang, and X. M. Lu, "Nonlinear absorption in an azo-containing ion liquid crystal polymer in the different excitation regimes," Synthetic Metals, vol. 160, no. 17-18, pp. 1896-1901, 2010.

[22] X. Li, X. Lu, Q. Lu, and D. Yan, "Photoorientation of liquid crystalline azo-dendrimer by nanosecond pulsed laser for liquid crystal alignment," Macromolecules, vol. 40, no. 9, pp. 33063312, 2007.

[23] P. Attri and E. H. Choi, "Influence of reactive oxygen species on the enzyme stability and activity in the presence of ionic liquids," PLoS ONE, vol. 8, no. 9, Article ID e75096, 2013.

[24] P. Attri, S.-H. Lee, S. W. Hwang et al., "Elucidating interactions and conductivity of newly synthesised low bandgap polymer with protic and aprotic ionic liquids," PLoS ONE, vol. 8, no. 7, Article ID e68970, 2013.

[25] P. Attri, K. Y. Baik, P. Venkatesu, I. T. Kim, and E. H. Choi, "Influence of hydroxyl group position and temperature on thermophysical properties of tetraalkylammonium hydroxide ionic liquids with alcohols," PLoS ONE, vol. 9, no. 1, Article ID e86530, 2014.

[26] P. Attri, S.-H. Lee, S. W. Hwang et al., "Effect of temperature on the interactions between low bandgap polymer and ionic liquids," Thermochimica Acta, vol. 579, pp. 15-21, 2014.

[27] P. Attri, P. Venkatesu, and A. Kumar, "Activity and stability of $\alpha$ chymotrypsin in biocompatible ionic liquids: enzyme refolding by triethyl ammonium acetate," Physical Chemistry Chemical Physics, vol. 13, no. 7, pp. 2788-2796, 2011.

[28] P. Attri and P. Venkatesu, "Thermodynamic characterization of the biocompatible ionic liquid effects on protein model compounds and their functional groups," Physical Chemistry Chemical Physics, vol. 13, no. 14, pp. 6566-6575, 2011.

[29] X. Pan, S. Xiao, C. Wang, P. Cai, X. Lu, and Q. Lu, "Photoinduced anisotropy in an azo-containing ionic liquid-crystalline polymer," Optics Communications, vol. 282, no. 5, pp. 763-768, 2009.

[30] F. Zhao, Z. Pan, C. Wang, Y. Zhou, and M. Qin, “Third-order nonlinear optical properties of an azobenzene-containing ionic liquid crystalline polymer," Optical and Quantum Electronics, vol. 46, no. 11, pp. 1491-1498, 2013.
[31] Y. He, X. Wang, and Q. Zhou, "Epoxy-based azo polymers: synthesis, characterization and photoinduced surface-reliefgratings," Polymer, vol. 43, no. 26, pp. 7325-7333, 2002.

[32] X. L. Wang, J. J. Yin, and X. G. Wang, "Epoxy-based polymers functionalized with bisazo chromophores: synthesis, characterization and photoresponsive behavior," Polymer, vol. 52, no. 15, pp. 3344-3356, 2011.

[33] J. B. Pawley, Handbook of Biological Confocal Microscopy, Kluwer Academic Publishers, Dordrecht, The Netherlands, 1995.

[34] M. Schmitt, B. Leimeister, L. Baia et al., "Characterization of diffusion processes of pharmacologically relevant molecules through polydimethylsiloxane membranes by confocal microresonance Raman spectroscopy," ChemPhysChem, vol. 4, no. 3, pp. 296-299, 2003.

[35] P. Attri, V. Bharti, Y. S. Kim et al., "Plasma modification of poly(2-heptadecyl-4-vinylthieno[3,4-d]thiazole) low bandgap polymer and its application in solar cells," Physical Chemistry Chemical Physics, vol. 16, no. 48, pp. 27043-27052, 2014. 

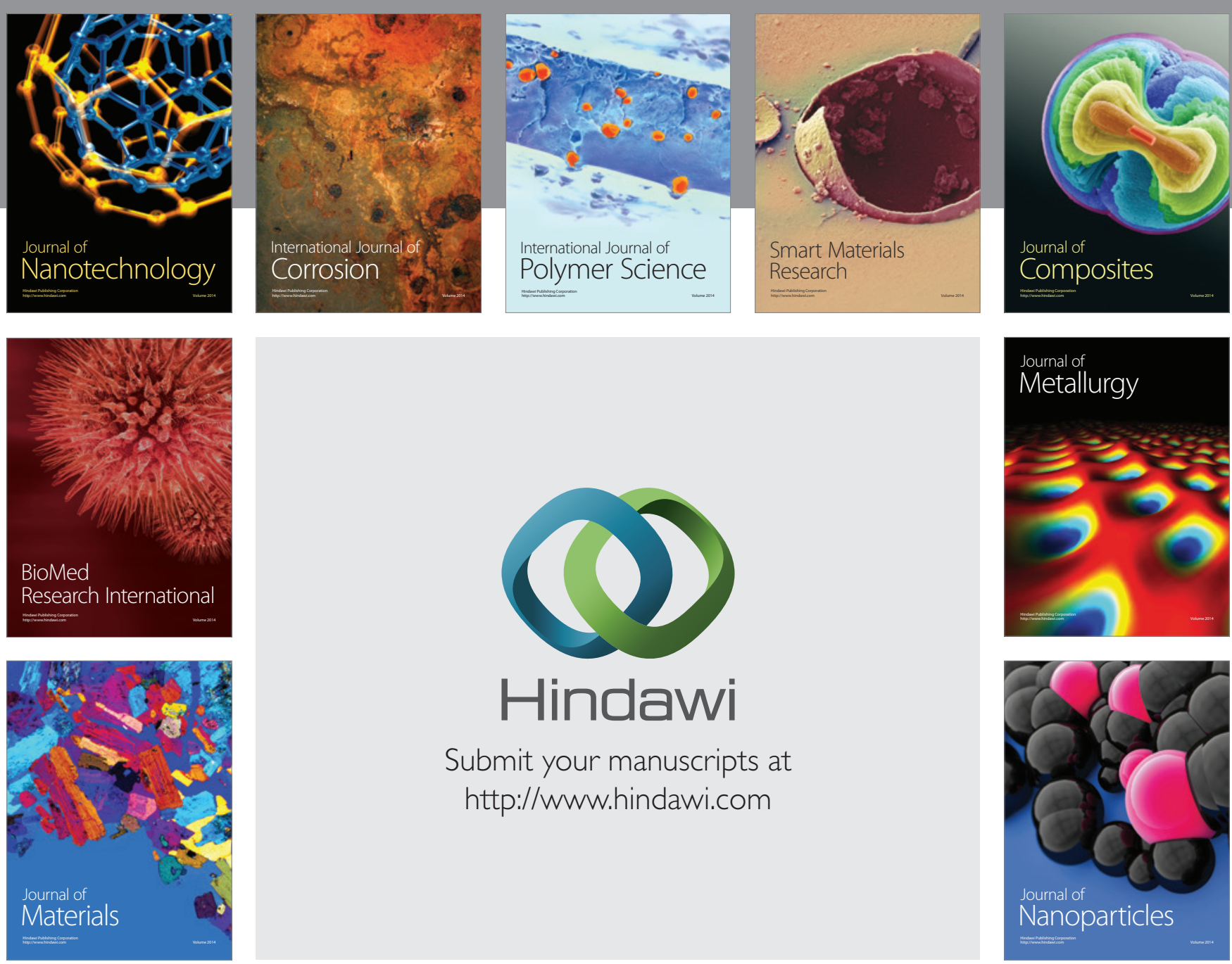

Submit your manuscripts at http://www.hindawi.com
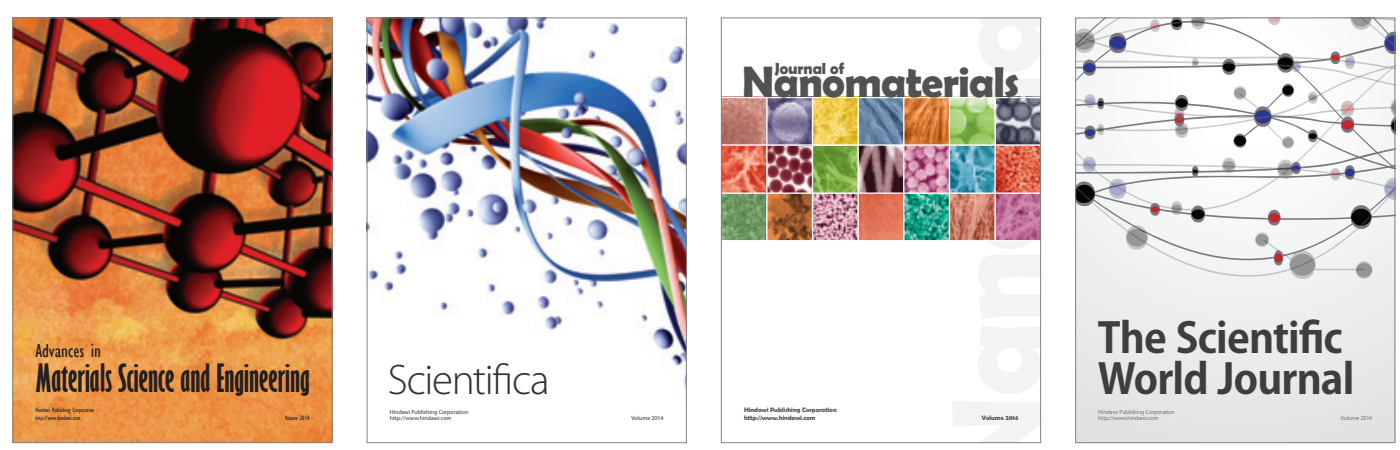

\section{The Scientific World Journal}
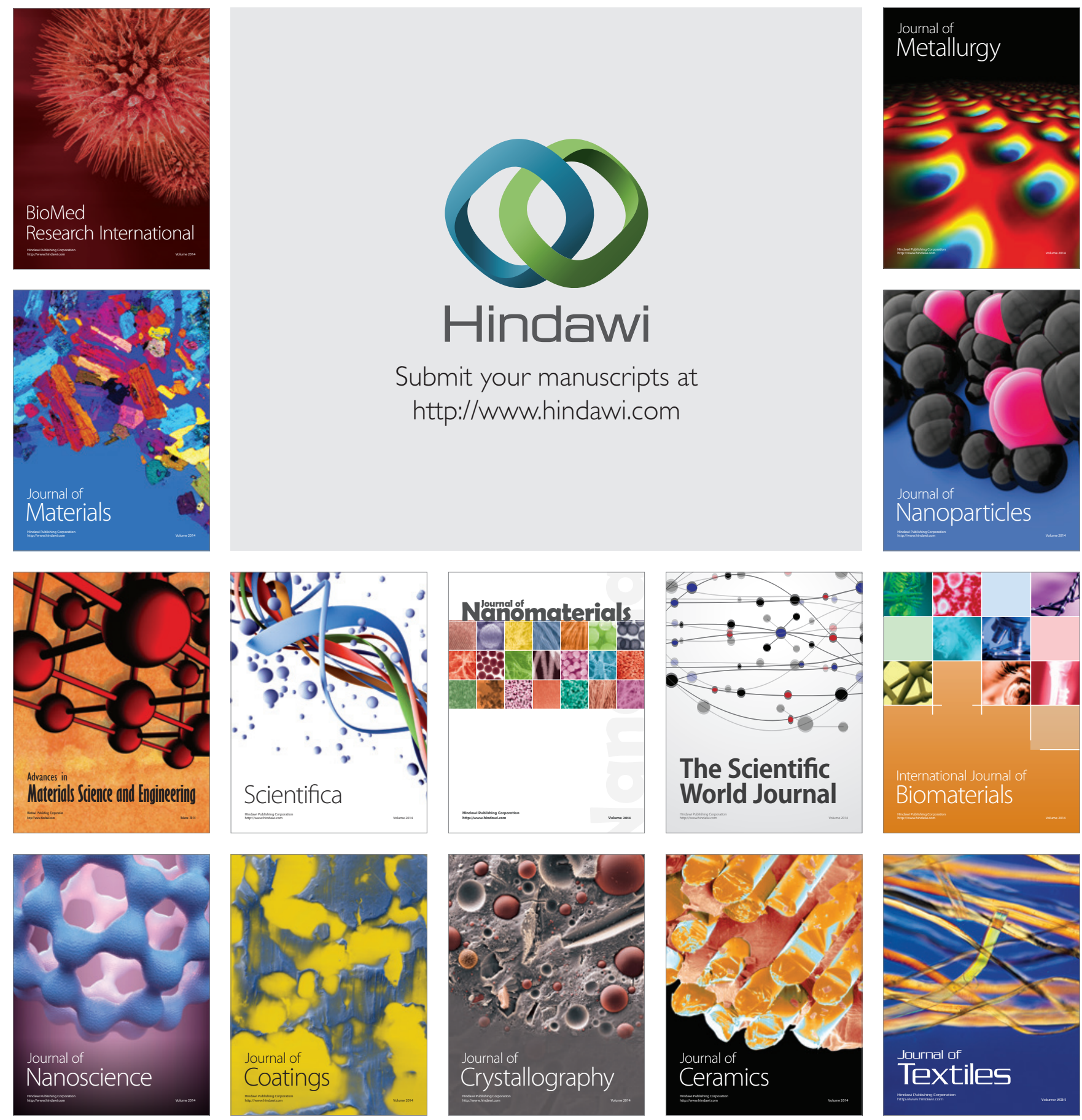